\title{
Application of translinguism in teaching foreign languages to students (specialty "Ecology")
}

\author{
Tatiana Baranova $^{1}$, Aleksandra Kobicheva $^{1,{ }^{*}}$, Elena Tokareva $^{1}$, and Evgenia Vorontsova $^{1}$ \\ ${ }^{1}$ Peter the Great St. Petersburg Polytechnic University, 195251, Polytechnicheskaya str., 29, \\ St.Petersburg, Russia
}

\begin{abstract}
This article explores the concept of translinguism and its application in the educational environment. The authors have developed a learning model that includes flipped classroom, face-to-face classes, team work and project-based learning. The study involved 3rd year students $(\mathrm{N}=26)$ of Peter the Great St. Petersburg Polytechnic University (SPbPU), studying in the field of "Ecology". During one semester (February 2020 June 2020), students studied the discipline "Spanish" in English according to proposed methodology. The study examined the impact of the proposed model on the study of the Spanish language and the development of translational competence. For the analysis descriptive statistics and pairsamples Students's t-test were conducted. Interviews were also conducted with students to analyze their perception of the new learning model. Generally, the overall quality of students' Spanish knowledge improved. According to the descriptive results, students developed their translingual competence significantly. Thus, it can be assumed that the proposed learning model positively influenced students' level of such competence. The results of the interview showed that students positively evaluate the proposed teaching model, and also consider it to be effective for learning Spanish and developing translingualism.
\end{abstract}

\section{Introduction}

Globalization, the activation of migration processes, including in the global digital environment, made it not only possible, but also necessary to study two or more foreign languages, aroused interest in various ethnic cultures, their specificity, points of contact, peculiarities of mutual influence. In order to ensure successful intercultural interaction, it is necessary to master completely new communication tools. We need a qualitative transition from standard interlingual communication, implying translation activity, to translinguism, which implies full awareness of the context of communication, the ability to decode information in various communication situations [1-3]. In this regard, in modern linguodidactics, the problems of studying the contacts of languages and cultures, the regularities of the formation of a bi- and polylingual personality, the specifics of the simultaneous and sequential development of various linguocultures are actualized [4]. A new aspect of the study of this problem is fixed in the concept of "translinguism", which

*Corresponding author: kobicheva92@gmail.com 
relatively recently entered the scientific circulation in various fields of humanitarian knowledge.

\subsection{Theoretical background}

An active study of the essence of translinguism in foreign science began in the 1990s, and at the turn of the century, this phenomenon attracted the attention of domestic linguists, culturologists, teachers, methodologists. For several years now, researchers in sociolinguistics and applied linguistics have been reading, attending presentations, discussing and, in many cases, working with translinguism - a term first coined by Sin Williams [5] and recently expanded as a theoretical and analytical concept in a broader sense. Ophelia Garcia [6] and other scholars [7-10] from English-speaking countries with a multilingual and multicultural context, where bilingual education is a long-standing goal.

Analysis of the scientific literature shows that in its most general form, under translinguism (or in other terminology - translingualism) is understood as the successful language practice of bi- and polylingual [6-11]. S. Canagarajah points to such important signs of translinguism as "smooth transition from one linguistic culture to another" in the process of communication, "lack of assimilation between linguocultures", which the user of two or more languages owns (or masters), "preservation of his linguocultural identity" [12].

In "Translanguaging: Language, Bilingualism, and Education" [13], Ophelia Garcia and Li Wei, two of the most prominent authors and researchers in the field of translinguism, present a key moment in the construction and development of the concept. The authors expand their concept of translinguism, building on concepts that they developed separately in previous works (for example, Garcia's distinction between subtractive, additive, and dynamic bilingualism [6] or Lee Wei's "translingual space" [10]) to cover a complex and complete theory about translinguism as a social practice and as a pedagogy. The book connects several elements. On the one hand, it examines translinguism as a social practice and its significance for our understanding of languages and the use of languages (part one) and translinguism in education (part two), analyzes the translinguism of both students and teachers, and pays special attention to the development of translinguism in pedagogy - that is, considering translinguism as a resource or asset that all children, teachers and trainee teachers must master $[14,15]$.

This research direction, namely the application of translinguism in teaching foreign languages, is today supported in the world linguodidactics $[6,11,12,16]$.

In recent years, a special - translingual - approach [16] to teaching communication in a foreign language has been formed in the world methodology. As noted by X. Chen, the focus of this approach, on the one hand, is the discursive practices of bi- and polylingual (how and why they use certain units and phenomena of the native and studied / studied languages in communication), on the other hand, this approach is aimed at the formation of the skills of correct communication in all languages that a person speaks, at the development of skills for fast, smooth and effective switching from one language code to another.

Let us give arguments in favor of the importance of including the translingual approach in the theoretical and methodological basis of the methodology for teaching foreign languages and introducing the concept of "translinguism" into its categorical and conceptual apparatus. The study of two or more languages and cultures is not a new subject of linguodidactic research. Traditionally, this direction was formalized using the terms bi- / multi- / polylingualism and their derivatives: bilingual, multilingual personality, etc. However, as Julia Hansen rightly notes in one of her works [17], while the term "bilingualism" means switching from one language code to another as a binary operation, 
and the meaning of the term "multilingualism" integrates the sign of proficiency in several languages, in the concept of "translinguism" the key is the relationship between languages.

The word "translingual" conveys the "idea of going beyond" any particular language [17]. J. Hansen also emphasizes the connection between translingualism and transculturalism, citing in this regard the statement of the philosopher Wolfgang Welch that transculturalism refutes the stability and immutability of cultural categories, fixing in its meaning the sign of dialogue, interaction of different cultures in the modern constantly changing world [17].

Domestic and foreign linguodidacts actively study such negative phenomena as pidginization of the language, negative interference, which results in the violation by a person studying a foreign language of the "rules for correlating contacting languages", various deviations from the norm in the use of the studied language [18, 19]. The prevention and overcoming of these phenomena in the speech of foreigners is traditionally carried out by increasing the training ("drilling") lexical and grammatical tasks, by introducing linguoculturological and linguistic-cultural tasks into practical courses. It is also necessary to take into account that the correct use of the studied (studied) languages requires special skills and abilities of "intercode switching", a quick, smooth transition to a different linguocultural coordinate system. According to Horner and $\mathrm{Lu} \mathrm{[20],} \mathrm{the}$ translingual approach "sees language differences not as an obstacle to overcome or a problem to be solved, but as a resource for creating meaning in writing, speaking, reading and listening" [20, p. 583]. It requires more critical attention to the use of language in different contexts and respect for differences within and between languages.

In this regard, we can conclude that in the meaning of the terms "translinguism", "translational skills", "translational personality" phenomena important for linguodidactics are recorded that are not reflected in traditional terminology, and the translational approach offers an "updated" view of traditional methods tasks, which allows you to more effectively form competence in communication in the target language; harmonize the processes of simultaneous or sequential formation in the cognitive system of a student of subsystems "responsible" for the linguistic and linguocultural aspects of communication; to optimize the models of bi- and polylingual cultural and language education.

Analysis of the literature identified the research question: how to develop translinguism among students of a non-linguistic university?

\section{Materials and methods}

All scientists involved in the educational process in higher schools are always looking for new and more effective approaches to transfer knowledge to students, endowing them with the competencies necessary for a rapidly developing world and market.

The study involved 3rd year students of Peter the Great St. Petersburg Polytechnic University (SPbPU), studying in the field of "Ecology". This educational program is implemented entirely in English. Figure 1 shows a model of teaching undergraduate students in the field of "Ecology" for the discipline "Spanish language" taught in English.

During one semester (February 2020 - June 2020), students studied the discipline "Spanish" in English according to our proposed methodology. It should be noted that these students studied Spanish for 2 years before and had a level of A2-B1. The group of students is interethnic, in connection with which the students were divided into small interethnic groups within their collective.

Each group on the Moodle platform was offered 4 identical texts on the topic under study in the following languages: English, Arabic, Chinese and Hindi (in accordance with the students' native languages). Within each group, respectively, there were students who had these languages as their mother tongue. During the semester, the following lexical 
topics were studied: environmental problems of Spain, education in Spain, Spanish cooking, the political system of Spain. Students independently studied these texts at home in their own language (flipped classroom). In the classroom lesson, students were offered case studies. During the lesson, students discussed in English the texts read in advance, built a work plan for the case study and search for a solution to the given problem (face-toface classroom). After that, the students had to prepare a presentation in their teams (team work) in Spanish about their proposed solution to the problem and answer the questions in Spanish (project-based classroom). Students performed such an algorithm for all 4 studied topics.

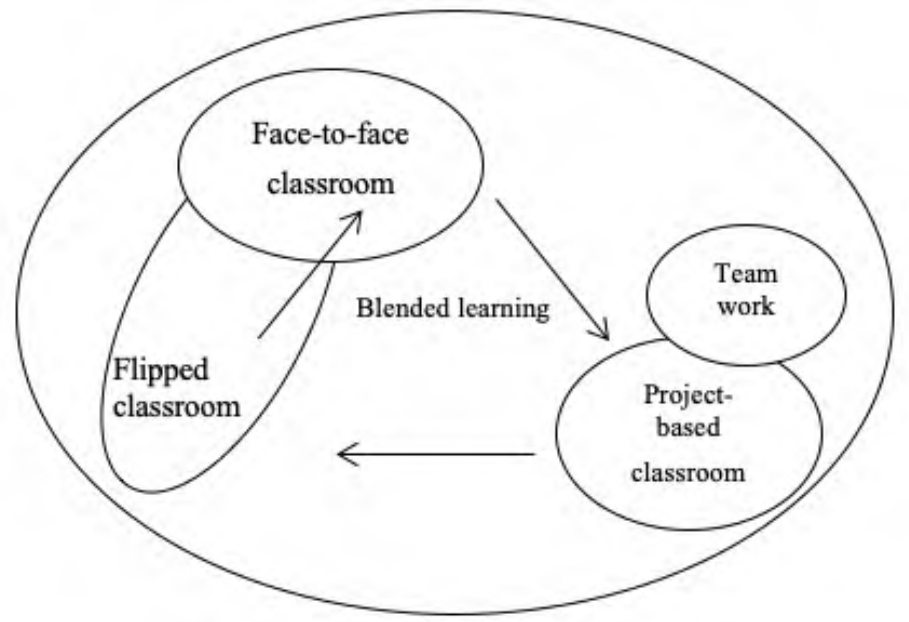

Fig. 1. Learning model for the discipline "Spanish language".

Before the experiment, we tested 3rd year bachelor students $(\mathrm{N}=26)$ to identify the level of English and Spanish proficiency. The test consisted of 4 parts: Listening, Reading, Writing and Speaking. Partly the test was conducted through the online platform Moodle that was developed for the St. Petersburg Polytechnic University (Listening, Reading, Writing) and partly on seminars (Speaking). The English language test was conducted to ensure that students have a sufficient level of English proficiency (we believe B2 is sufficient). Spanish test's (reading, listening, writing and speaking) records were examined and compared to reveal the effect of proposed learning approach. To gain a clear understanding of the application of the new method, we conducted a deep interview to determine if the teaching model contributes to the development of translinguism from students' perspective, as well as to identify factors that potentially contribute to their effectiveness. In addition, before and after the course, students passed a test to check the formation of their translingual competence. The test items were based on the lexical topics studied in the classroom. The test item was presented in English and the answer options were presented in Spanish. There were also a number of open questions, involving the presentation of students' opinions. Such questions were also presented in English, and students were asked to answer in Spanish.

This paper is based on the following research questions:

1.Is there a significant difference in the level of Spanish proficiency before and after the course?

2.Does the proposed teaching methodology contribute to the formation and development of translingual competence?

3. If a proposed learning model is efficient from the students' perspective?

To obtain the data we used both quantitative and qualitative data (Table 1). 
Table 1. Data collection.

\begin{tabular}{|c|c|c|}
\hline Results & Sort of data collection & Type of data \\
\hline Translingual competence & Scores on testing & quantitative \\
\hline Spanish proficiency & Scores on testing & quantitative \\
\hline $\begin{array}{c}\text { Efficiency of the learning } \\
\text { model from students' } \\
\text { perspective }\end{array}$ & Interview & qualitative \\
\hline
\end{tabular}

For the analysis descriptive statistics and pair-samples Students's t-test were conducted.

\section{Results}

\subsection{Academic achievements}

\subsubsection{Spanish proficiency}

The students' testing results on Spanish proficiency are presented in Table 2.

Table 2. Descriptive results of Pre-test and Post-test on Spanish.

\begin{tabular}{|c|c|c|c|c|}
\hline \multirow{2}{*}{ Category } & Test & $\begin{array}{c}\text { Results (average } \\
\text { mean) }\end{array}$ & SD & \multirow{2}{*}{ t-value } \\
\hline \multirow{2}{*}{ Listening } & Pre-test & 59,88 & 8,44 & \multirow{2}{*}{$2,4^{*}$} \\
\cline { 2 - 4 } & Post-test & 64,48 & 8,04 & \multirow{2}{*}{$5,6^{* * *}$} \\
\hline \multirow{2}{*}{ Reading } & Pre-test & 65,12 & 7,87 & \multirow{2}{*}{$2,2^{*}$} \\
\cline { 2 - 4 } & Post-test & 76,88 & 7,63 & \multirow{2}{*}{$6,0^{* * *}$} \\
\hline \multirow{2}{*}{ Writing } & Pre-test & 68,68 & 8,11 & 8,8 \\
\cline { 2 - 4 } & Post-test & 72,04 & 8,48 & \multicolumn{2}{|c}{} \\
\hline \multirow{2}{*}{ Speaking } & Pre-test & 62,16 & 82,84 & \multicolumn{2}{|c}{} \\
\cline { 2 - 4 } & Post-test & & & \\
\hline
\end{tabular}

$* \mathrm{p}<0,05 ; * * \mathrm{p}<0,01 ; * * * \mathrm{p}<0,001$

Generally, the overall quality of students' Spanish knowledge in 4 categories improved. Results' comparison of the two tests (before and after the course) of all participants in the experiment indicates that the improvements in reading and speaking were significant on $\mathrm{p}<0,001$ level. In the listening and writing categories students' achievements were less progressive, but due to Student's t-test they were also significant on $p<0,05$ level (Table 2 ). Hence, the results approve the efficiency of the proposed educational model firstly for Spanish learning purposes.

\subsubsection{Translingual competence}

The students' testing results on translingual competence are presented in Table 3.

Table 3. Descriptive results of Pre-test and Post-test on Translingual competence.

\begin{tabular}{|c|c|c|c|c|}
\hline Indicator & Test & $\begin{array}{c}\text { Results (average } \\
\text { mean) }\end{array}$ & SD & t-value \\
\hline $\begin{array}{c}\text { Translingual } \\
\text { competence }\end{array}$ & Pre-test & 59,93 & 8,13 & \multirow{2}{*}{$3,19^{* *}$} \\
\cline { 2 - 4 } & Post-test & 68,19 & 6,01 & \\
\hline
\end{tabular}

$* \mathrm{p}<0,05 ; * * \mathrm{p}<0,01 ; * * * \mathrm{p}<0,001$

According to the descriptive results, students developed their translingual competence significantly. Thus, it can be assumed that the proposed learning model positively influenced students' level of such competence. 
The achievements are considered to be positive with a total value being above $70 \%$ (corresponding to the answers "good" and "quite right") in the level of Spanish proficiency. The level of translingual competence regarded high when the value is above $65 \%$. According to test result the students were divided into four groups or quadrants (see Figure 2).

- Group 1 (Q1) represents students with low level of translingual competence but good knowledge of Spanish

- Group 2 (Q2) represents students with high level of translingual competence but poor knowledge of Spanish

- Group $3(\mathrm{Q} 3)$ represents students with low level of translingual competence and poor knowledge of Spanish

- Group 4 (Q4) represents students with high level of translingual competence and good knowledge of Spanish.

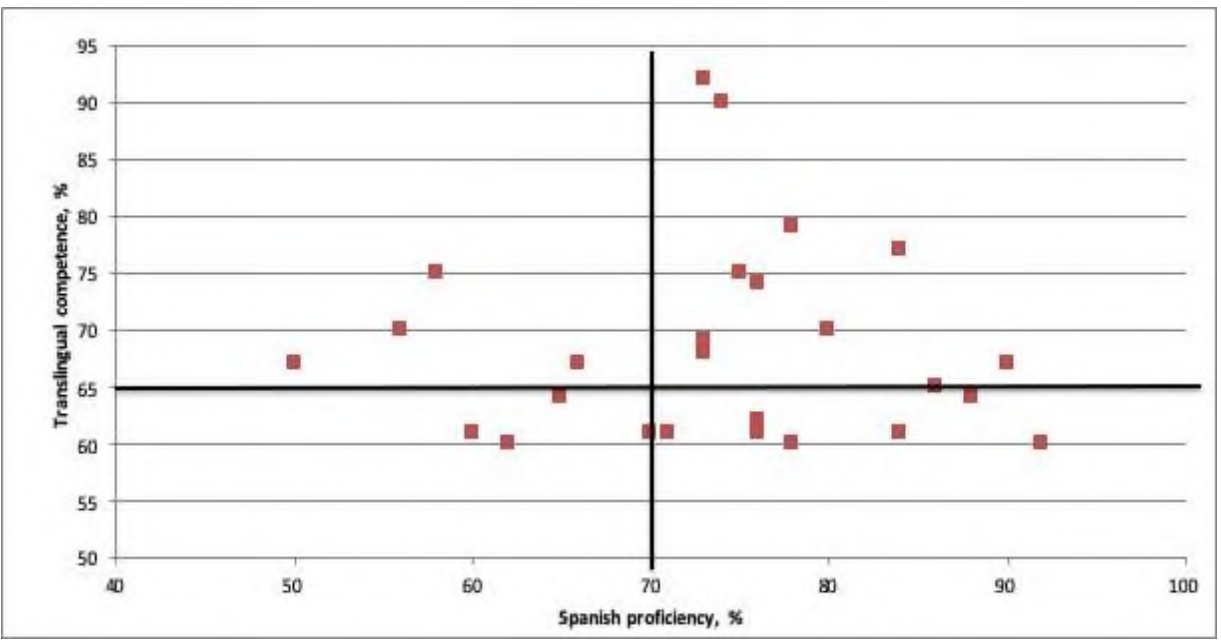

Fig. 2. Spanish proficiency and translingual competence.

Most students had both high level of translingual competence and good knowledge of Spanish (Q1, 53.852\%), followed by students who had low level of translingual competence and good knowledge of Spanish (Q2, 37.222\%), and lastly students with neither high nor low level of translingual but poor knowledge of Spanish (Q3, 4,483\%; Q4, $4,443 \%)$, respectively.

\subsection{Interview on the learning model efficiency}

After the test three students were chosen from each quadrant for a semi-structured interview aimed to identify their assessment of the course. The length of the interview was 20 min for each student. For further detailed analysis each interview was recorded, examined thoroughly and summarized. The following questions were asked:

- What is your opinion about the offered methodology?

- What difficulties did you face with?

- Did the offered methodology have a considerable impact on your level of Spanish?

- Did the offered methodology help you improve your ability to switch between the languages?

- Which part of the project work seemed to be the most successful?

- Which part of the project work seemed to be the most difficult?

- Would you like to continue using the offered methodology? 
The majority of the respondents admitted that such format of project work seemed unusual and exciting to them. ("It was the first time when I had to switch between the languages and work in the multination team with Spanish being the middle language"). However, the students from Q3 claimed that their poor Spanish proficiency faced with some difficulties connected with explaining some basic concepts of the articles to the participants of their groups.

The students claimed that by the end of the project they became more confident and comfortable working with the representatives of different cultures. Nevertheless, it took the respondents some time to get used to the conditions and specific features of the project. They mentioned that "It was rather complicated to motivate some participants to work as a group, as they felt frustrated".

The majority of the respondents found the topics under the discussion and materials provided for the group project captivating. However, students from Q2 found it sometimes difficult to explain some special terms and concepts to their groupmates. Nevertheless, they expressed satisfaction with the overall result of the project.

At the same time almost all respondents underlined that such a project was a priceless experience for them, it let them improve their Spanish speaking skills, helped them develop code switching skills (although they found it challenging at the beginning), motivated them to research their study topics and learn about different cultures of their groupmates.

Finally, the respondents concluded that they would like to continue studying using the offered methodology as it allows them to dive deeper into cross-cultural communication and learn more about business in the countries all over the world.

\section{Discussion}

Generally, the overall quality of students' Spanish knowledge improved. Results' comparison of the two tests (before and after the course) of all participants in the experiment indicates that the improvements in reading and speaking were significant. Hence, the results approve the efficiency of the proposed educational model firstly for Spanish learning purposes.

According to the descriptive statistics, students developed their translingual competence significantly too. According to the results' comparison of the two tests (before and after the course) of all participants in the experiment, it can be assumed that the proposed learning model positively influenced students' level of such competence.

According to test result the students were divided into four groups or quadrants. The results implied that students with high level of translingual competence were more likely to perform well in Spanish class, and that more analysis is required regarding the performance of students with low translingual competence.

According to the interview results, the students expressed their satisfaction with the proposed teaching model, although at first they faced various problems. However, the students expressed a desire to continue their studies according to the proposed model.

\section{Conclusions}

In our study we aimed to examine the students' level of Spanish proficiency and translingual competence as well as to determine whether the proposed educational model was efficient for language learning purposes and intercultural communications. The analysis of students' testing results showed that their Spanish proficiency level was improved, especially in the categories of reading and speaking. The results of students' 
translingual competence development was also significant. These facts made it possible to confirm the positive influence of the course.

The results of the interview showed that students positively evaluate the proposed teaching model, and also consider it to be effective for learning Spanish and developing translingualism.

When developing the training model, we relied on the research of many scientists who study translinguism $[6,8,10,11,16]$. However, the hallmark of our approach is the use of a multinational group, in which not only Spanish and English are used, but also mother tongues, which differ among students. We also applied translinguism not only in exercises, but throughout the entire learning process, making the process of switching between language codes natural.

However, our research has limitations. We studied the behavior of only one group of students, which is a small number. In addition, all students had a high level of English, were familiar with each other and could use any languages for communication and collaboration outside the classroom. In future studies, we will examine the effectiveness of the proposed model for more participants.

\section{References}

1. S. K. Antipov, A. A. Bocharov, A. Kobicheva and E. E. Krasnozhenova, Assessment of Region Economic Development on the Basis of Neural Network Model. IOP Conf. Ser.: Earth and Envir. Sci. 302, 012094 (2019) DOI: 10.1088/1755-1315/302/1/012094

2. T. Baranova, A. Kobicheva, E. Tokareva, Web-based Environment in the Integrated Learning Model for CLIL-Learners: Examination of Students' and Teacher's Satisfaction. In: Antipova T., Rocha A. (eds) Digital Science 2019, DSIC 2019, Advances in Intelligent Systems and Computing 1114 (2020)

3. T.A. Baranova, A.M. Kobicheva, E.Y. Tokareva, Effects of an Integrated Learning Approach on Students' Outcomes in St. Petersburg Polytechnic University, ACM Inter. Conf. Proc. Ser. 77-81 (2019) doi.org/10.1145/3369199.3369245

4. E. B. Volodarskaya, A. S. Grishina and L. I. Pechinskaya, Virtual Learning Environment in Lexical Skills Development for Active Vocabulary Expansion in NonLanguage Students Who Learn English, 2019 12th International Conference on Developments in eSystems Engineering (DeSE), Kazan, Russia, 388-392 (2019)

5. N. Hornberger, H. Link, Translanguaging and Transnational Literacies in Multilingual Classrooms: A Biliteracy Lens, Inter. J. of Bilin. Educ. and Bilingu. 15, 261-278 (2012) 10.1080/13670050.2012.658016

6. O. García, Bilingual education in the 21st century: A global perspective (Malden/Oxford: Wiley/Blackwell, 2009)

7. A. Blackledge, A. Creese, Multilingualism: A critical perspective (London: Continuum, 2010)

8. A. Canagarajah, Negotiating Translingual Literacy: An Enactment. Research in the Teaching of English 48(1), 40-67 (2013)

9. A. Creese, A. Blackledge, Translanguaging in the bilingual classroom: A pedagogy for learning and teaching? Modern Language Journal 94(i), 103-115 (2010)

10. L. Wei, Moment analysis and translanguaging space: Discursive construction of identities by multilingual Chinese youth in Britain, J. of Pragm. 43, 1222-1235 (2011)

11. C. Celic, K. Seltzer, Translanguaging: A CUNY-NYSIEB guide for educators (The Graduate Center, The City University of New York: CUNY-NYSIEB, 2011) 
12. S. Canagarajah, Codemeshing in academic writing: Identifying teachable strategies of translanguaging, Mod. Lang. J. 95(3), 401-417 (2011)

13. O. García, L. Wei, Translanguaging: Language, bilingualism and education (London: Palgrave Macmillan, 2014)

14. Y.L. T. Ting, T. Chadwick, Language Awareness in Teaching: A Toolkit for Content and Language Teachers, J. of Imm. and Content-Based Lang. Ed. 3, 157-160 (2015) 10.1075/jicb.3.1.09tin

15. S. Sugiharto, Translingualism in action: Rendering the Impossible Possible, The J. of Asia TEFL 12, 2, 125-154 (2015)

16. X. Chen, Translingual Practices in the First-year International Students' English: Academic Writing, ITJ 14, 1, 25-50 (2017)

17. J. Hansen, Introduction: Translingualism and transculturality in Russian contexts of translation, Translation Studies 11, 113-121 (2018)

18. J.J. Gumperz, Discourse strategies (New York: Cambridge University, 1982)

19. R. Otheguy, O. García, W. Reid, Clarifying translanguaging and deconstructing named languages: A perspective from linguistics, Appl. Ling. Rev. 6(3), 281-307 (2015)

20. M. Lu, B. Horner, Translingual Literacy, Language Difference, and Matters of Agency, College English 75(6), 582-607 (2013) 